\title{
Learning Media Applications and Introduction of Javanese Gamelan Musical Instruments Based on Android
}

\section{Aplikasi Media Pembelajaran Dan Pengenalan Alat Musik Gamelan Jawa Berbasis Android}

\author{
Muchammad Sofyan Ariefbillah ${ }^{1}$, Cindy Taurusta ${ }^{2}$ \\ [161080200255@umsida.ac.id, cindytaurusta@umsida.ac.id] \\ ${ }^{1)}$ Program Studi Informatika, Universitas Muhammadiyah Sidoarjo, Indonesia
}

\begin{abstract}
The role of technology, especially information technology, is very helpful in people's lives, from the aspects of education, business, to the health sector. In this day and age, many modern musical instruments have begun to shift the existence of traditional music, especially this typical Javanese musical instrument, namely Gamelan. With the development of the times, the public's interest in this traditional Gamelan instrument is decreasing. So that this application has a problem formulation, namely how to design and create an android application that concerns the introduction and learning of various types of gamelan musical instruments. This study aims to produce an application for the introduction of an Android-based gamelan instrument that can be used by all groups to be more familiar with and interested in learning and preserving gamelan instruments. This research was conducted with a survey method to obtain data or opinions to test this application. Based on the research that has been done, a conclusion can be drawn with this research which results in an application that can help and make it easier for people to know the various types of Javanese gamelan.
\end{abstract}

Keyword : Aplikasi, Learning, Gamelan, Android

\begin{abstract}
Abstrak-Peran teknologi khususnya teknologi informasi sangat membantu dalam kehidupan masyarakat mulai dari aspek pendidikan, bisnis, hingga dalam bidang kesehatan. Di zaman sekarang ini banyak alat musik modern yang mulai menggeser adanya musik tradisional khususnya alat musik khas dari Jawa ini yaitu Gamelan. Semakin berkembangnya zaman, minat masyarakat terhadap alat musik tradisional Gamelan ini semakin menurun. Sehingga aplikasi ini memiliki rumusan masalah yaitu bagaimna merancang dan membuat aplikasi android yang menyangkut tentang pengenalan serta pembelajaran berbagaai jenis alat musk gamelan. Penelitian ini mempunyai tujuan yaitu untuk menghasilkan aplikasi pengenalan alat musik gamelan berbasis android yang dapat digunakan oleh semua kalangan agar lebih mengenal dan berminat untuk belajar dan melestarikan alat musik gamelan. Penelitian ini dilakukan dengan metode survei yaitu untuk mendapatakan data atau pendapat untuk menguji aplikasi ini. Berdasarkan penelitian yang telah dilakukan, didapat sebuah kesimpulan dengan adanya penelitian ini yang menghasilkan sebuah aplikasi yang dapat membantu dan mempermudah masyarakat dalam mengetahui berbagai macam jenis gamelan jawa.
\end{abstract}

Kata Kunci : Aplikasi, Pembelajaran, Gamelan, Android,

\section{I.PENDAHULUAN}

Tingginya teknologi dan ilmu pengetahuan sehingga mendorong masyarakat untuk mencari sarana yang tepat. Peran teknologi khususnya teknologi informasi sangat membantu dalam kehidupan masyarakat mulai dari aspek pendidikan, bisnis, hingga dalam bidang kesehatan. Penerapan teknologi sistem informasi dalam lingkup masyarakat sangat dibutuhkan dalam kehidupan sehari-hari agar memperoleh wawasan yang luas. Suatu contoh bagian dalam kehidupan sehari-hari adalah smartphone yang pada umumnya berbasis android.

Android merupakan suatu sistem operasi yang berbasis linux untuk telepon pintar smartphone ataupun pada komputer tablet. [1]

Beraneka ragam budaya yang ada di indonesia dari Sabang sampai dengan Merauke. Banyak jenis kebudayaan seperti halnya tarian, adat istiadat, dan alat musik tradisional yang secara turun temurun dilestarikan oleh masyarakat. Di pulau Jawa sendiri terdapat beraneka ragam budaya salah satunya yaitu alat musik tradisional Gamelan.

Gamelan berasal dari kata nggamel (dalam bahasa jawa) / gamel yang berarti memukul/menabuh, diikuti akhiran "an" yang menjadikannya sebagai kata benda. Sedangkan istilah gamelan mempunyai arti sebagai satu kesatuan alat musik yang dimainkan bersama. [10]

Di zaman sekarang ini banyak alat musik modern yang mulai menggeser adanya musik tradisional khususnya alat musik khas dari Jawa ini yaitu Gamelan. 
Seni gamelan jawa mengandung nilai-nilai historis dan filosofi bagi bangsa Indonesia. Dikatakan demikian sebab gamelan jawa merupakan salah satu seni budaya yang diwariskan oleh para pendahulu dan sampai sekarang masih banyak digemari serta ditekuni. [4]

Semakin berkembangnya zaman, minat masyarakat terhadap alat musik tradisional Gamelan ini semakin menurun karena kurangnya wadah atau media.

Media merupakan sarana penyalur pesan atau informasi belajar yang hendak disampaikan oleh sumber pesan kepada sasaran atau penerima pesan tersebut. [10]

Sehingga perlu adanya media pengenalan alat musik Gamelan agar masyarakat lebih mengenal dan memahami berbagai jenis Gamelan khususnya yang ada di pulau Jawa.

Gamelan merupakan seperangkat alat musik khas Indonesia yang kelengkapan instrumennya dapat disejajarkan dengan simfoni orkestra. Sebagaimana alat musik pada umumnya, Gamelan di Indonesia dapat kita temukan di berbagai daerah, terutama Bali, Jawa, dan Sunda. [2]

Aplikasi pengenalan alat musik Gamelan Jawa dapat diterapkan pada Smarthphone berbasis android dikarenakan gadget berbasis android hingga saat ini alat yang banyak dipakai seluruh masyarakat, oleh sebab itu aplikasi ini bisa memberi wawasan tentang gamelan. Penggunaan media dalam sutu proses belajar mengajar bertujuan agar pembelajaran berlangsung secara tepat dan berdaya guna, sehingga dengan demikian mutu pendidikan dapat ditingkatkan. [5]

Untuk memperoleh kemudahan masalah tersebut, bisa dengan cara membaut aplikasi android agar semua kalangan bias menggunakannya Penjelasan diatas membuat penulis tertarik untuk membahas masalah tersebut menjadi tugas akhir dengan judul "Aplikasi Media Pembelajaran dan Pengenalan Alat Musik Gamelan Jawa Berbasis Android”. Aplikasi ini mengenalkan serta memberikan pembelajaran tentang alat musik tradisional Gamelen. Diharapkan dengan adanya aplikasi ini dapat meningkatkan minat masyarakat terhadap alat musik gamelan.

\section{II.METODE PENILITIAN}

Pengumpulan data yang digunakanan adalah menguunakan metode survei yaitu mengumpulkan data atau pendapat tentang aplikasi yang digunakan melalui lembar kusioner yang diberikan kepada responden.

\section{A. Alur Penelitian}

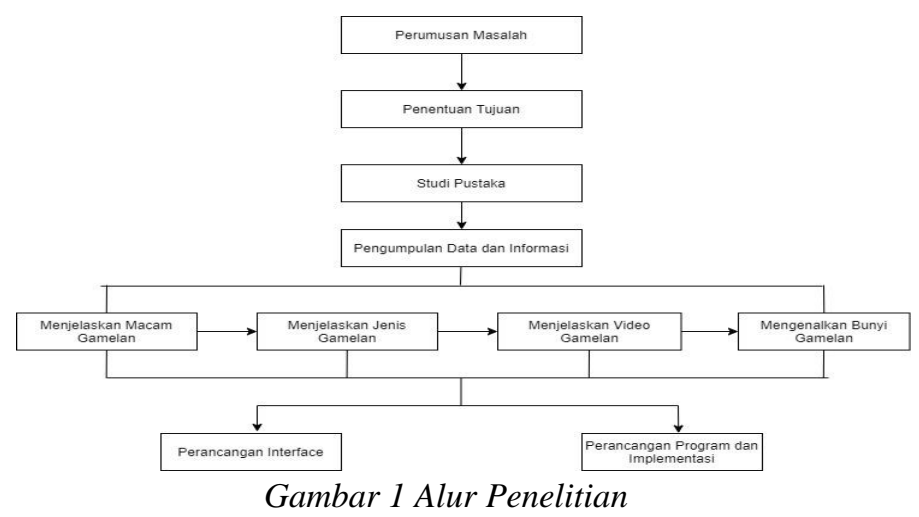

\section{B. Use Case}

Use case adalah pemodelan untuk sistem informasi yang akan dibuat. Use case dibuat untuk mengetahui fungsifungsi yang ada di dalam sistem informasi dan siapa saja yang berhak menggunakan fungsi-fungsi tersebut. [7] 


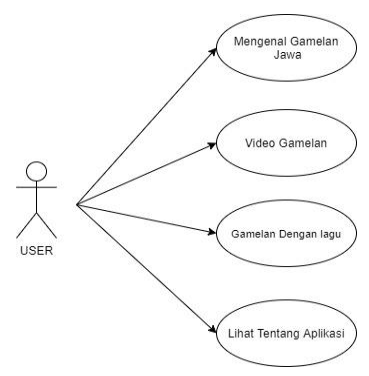

Gambar 2 Use Case Aplikasi Gamelan

Keterangan :

Yang dapat dilakukan leh User yaitu memilih menu mengenal gamelan jawa, video gamelan, belajar gamelan dengan lagu dan melihat tentang aplikasi.

\section{Data Flow Diagram (DFD)}

\section{DFD Level 0}

Data Flow Diagram (DFD) merupakan diagram yang menggambarkan aliran data dalam suatu sistem ke entitas atau sebaliknya. DFD juga dapat diartikan sebagai teknik grafis yang menggambarkan alir data dari input atau masukan menuju atau output. [8]

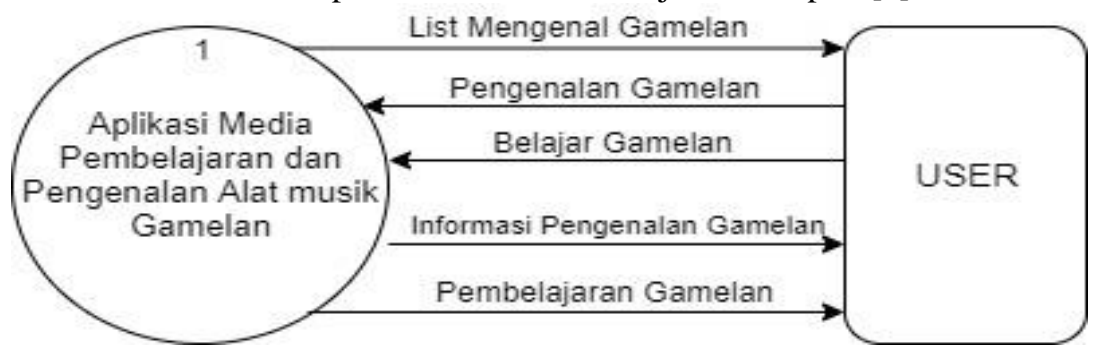

Gambar 3 DFD level 0 Aplikasi Gamelan

Keterangan :

Aplikasi menyediakan list pada menu Mengenal Gamelan dan Belajar Gamelan, kemudian user memilih menu pengenalan atau belajar Gamelan, selanjutnya Aplikasi akan memberikan informasi tentang Gamelan dan memberikan pembelajaran Gamelan kepada User.

\section{Flowchart}

Flowchart adalah gambaran secara grafik dari langkah-langkah dan urutan suatu program. Pada dasarnya mempengaruhi penyelesaian masalah yang harus di selesaikan lebuh lanjut. [9] 
Procedia of Engineering and Life Science Vol. 1. No. 2 Juni 2021

Seminar Nasional \& Call Paper Fakultas Sains dan Teknologi (SENASAINS 2st)

Universitas Muhammadiyah Sidoarjo

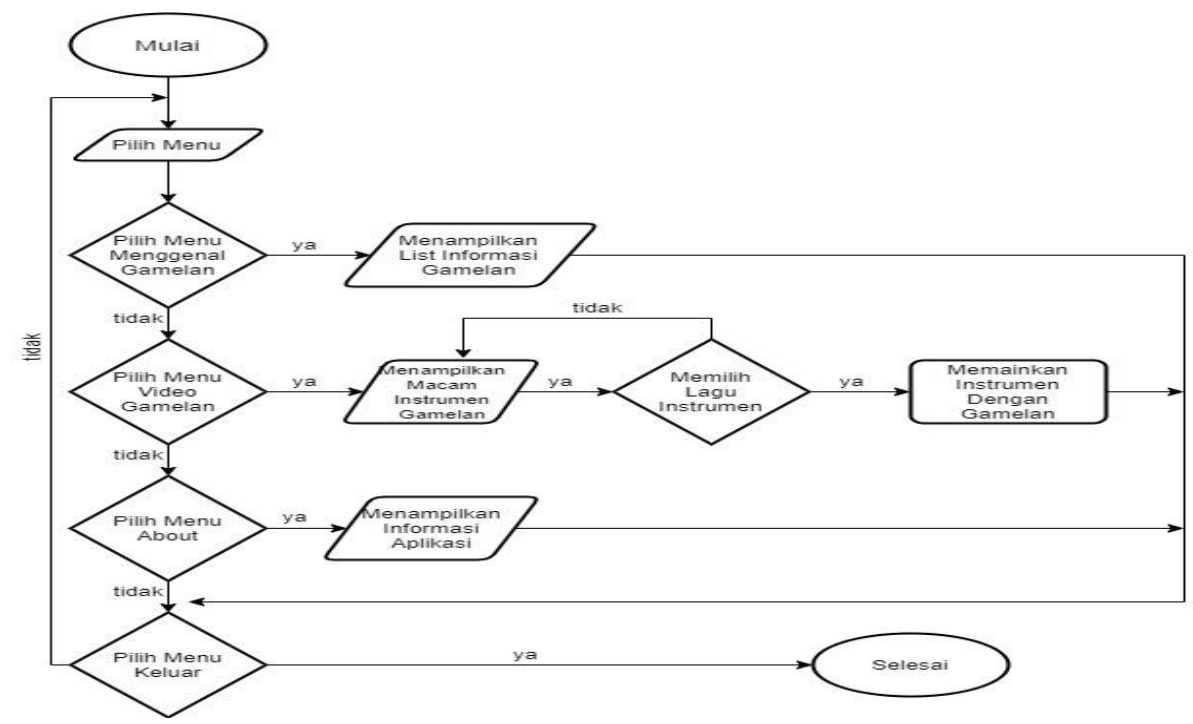

Gambar 4 Flowchart Aplikasi Gamelan

\section{E. Sequence diagram}

Merupakan diagram yang menunjukkan aliran fungsional dalam use case. Sequence adalah satu dari dua interaksi diagram yang menggambarkan objek-objek yang berhubungan dengan use case. [6]

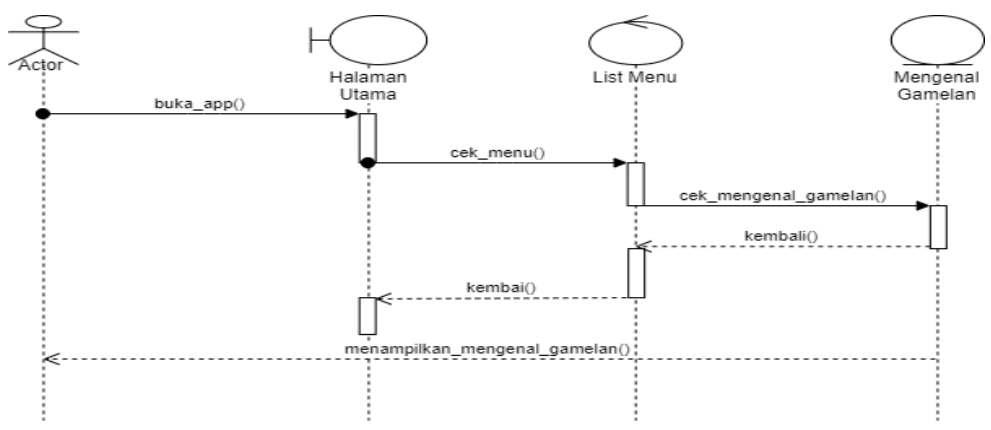

Gambar 5 sequence diagram Aplikasi Gamelan

\section{HASIL DAN PEMBAHASAN}

\section{A. Tampilan Program}

1. Halaman Menu Utama

Pada halamn menu utama ini menampilkan menu - menu yang ada di apikasi ini, yang terdiri dari menu Mengenal gamelan, Video gamelan dan Tentang. 

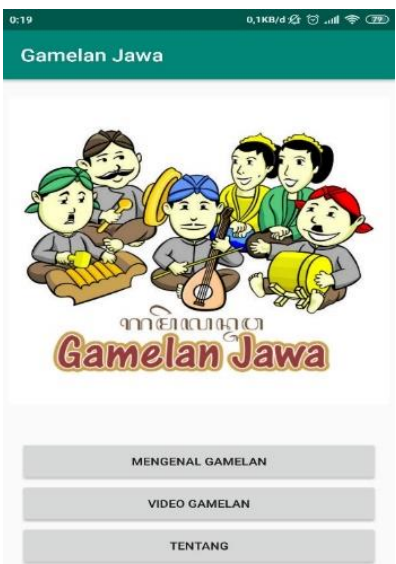

Gambar 6 Halaman Utama Aplikasi

Pada menu Mengenal Gamelan berisikan tentang macam-macam informasi tentang gamelan yang meliputi nama, jenis dan fungsinya. Menu video gamelan berisi video dari masing - masing gamelan Dan untuk menu Tentang berisikan deskripsi singkat tentang aplikasi dan versi aplikasi.

2. Halaman Menu Mengenal Gamelan

Pada halaman menu mengenal gamelan ini menampilkan berbagai macam jenis gamelan jawa.

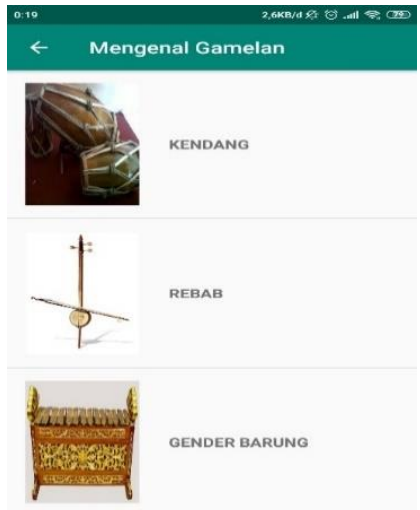

Gambar 7 Halaman Menu Mengenal Gamelan

Berbagai macam jenis gamelan yang disediakan dalam menu ini akan berisi tentang informasi dari jenis gamelan yang ingin dipilih.

3. Halaman Isi Menu Mengenal Gamelan

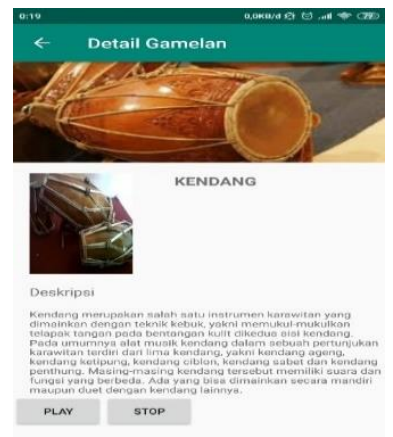

Gambar 8 Isi Mengenal Gamelan 
Halaman ini berisi tentang deskripsi atau penjelasan dari jenis gamelan yang telah di pilih. Di halaman ini juga terdapat tombol untuk memainkan lagu instrumen dari jenis gamelan yang dipilih.

4. Halaman Video Gamelan

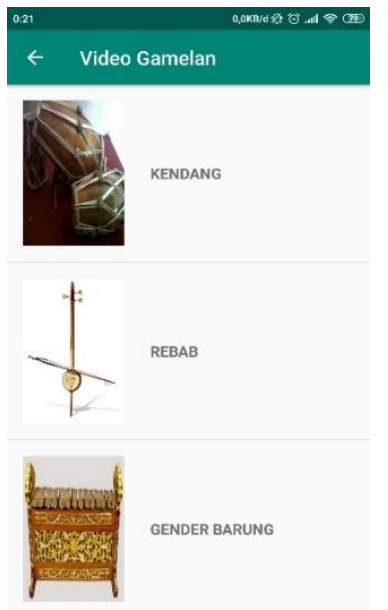

\section{Gambar 9 Halaman Video Gamelan}

Pada halaman Video Gamelan ini berisikan berbagai macam jenis video dari berbagai macam jenis gamelan yang akan dipilih oleh pengguna.

5. Halaman Isi Video Gamelan

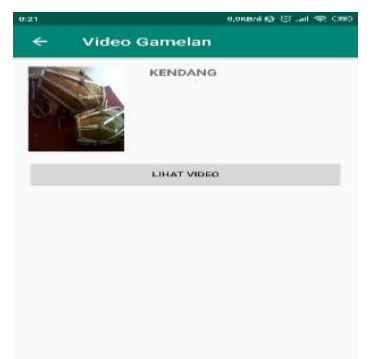

Gambar 10 Halaman Isi Video Gamelan

Pada halaman ini berisi tentang jenis gamelan yang telah dipilih dan terdapat tombol lihat video yang akan menampilkan video gamelan secara online kepada pengguna.

6. Halaman Menu Tentang

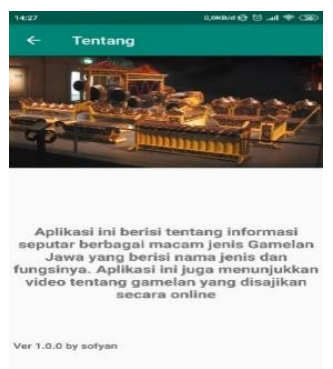


Procedia of Engineering and Life Science Vol. 1. No. 2 Juni 2021

Seminar Nasional \& Call Paper Fakultas Sains dan Teknologi (SENASAINS 2 ${ }^{\text {st }}$ )

Universitas Muhammadiyah Sidoarjo

Pada halaman ini berisi tentang deskripsi singkat tentang aplikasi ini dan berisi versi aplikasi.

\section{B. Pengujian Aplikasi}

Tahap akhir dari pembuatan aplikasi ini adalah tahap pengujian. Proses pengujian dilakukan dengan cara memerikan pertanyaan seputar apliaksi menggunakan kusioner dan memberikan responden untuk menjalankan aplikasi.

\begin{tabular}{|c|c|c|}
\hline Pertanyaan & Jawaban & Frekuensi \\
\hline \multirow{3}{*}{$\begin{array}{l}\text { Apakah informasi yang disediakan oleh aplikasi } \\
\text { ini mudah dimengerti? }\end{array}$} & Setuju & 24 \\
\hline & $\begin{array}{l}\text { Tidak } \\
\text { Setuju }\end{array}$ & 0 \\
\hline & Tidak Tau & 2 \\
\hline \multirow{3}{*}{$\begin{array}{l}\text { Apakah pengguanaan menu atau fitur aplikasi } \\
\text { menu mudah digunakan? }\end{array}$} & Setuju & 25 \\
\hline & $\begin{array}{l}\text { Tidak } \\
\text { Setuju }\end{array}$ & 0 \\
\hline & Tidak Tau & 1 \\
\hline \multirow[t]{3}{*}{ Apakah aplikasi nyaman digunakan? } & Setuju & 23 \\
\hline & $\begin{array}{l}\text { Tidak } \\
\text { Setuju }\end{array}$ & 0 \\
\hline & Tidak Tau & 3 \\
\hline \multirow{3}{*}{$\begin{array}{l}\text { Secara keseluruhan apakah penggunaan aplikasi } \\
\text { ini memuaskan? }\end{array}$} & Setuju & 20 \\
\hline & $\begin{array}{l}\text { Tidak } \\
\text { Setuju }\end{array}$ & 1 \\
\hline & Tidak Tau & 5 \\
\hline \multirow[t]{3}{*}{ Apakah aplikasi ini sesuai kebutuhan? } & Setuju & 20 \\
\hline & $\begin{array}{l}\text { Tidak } \\
\text { Setuju }\end{array}$ & 2 \\
\hline & Tidak Tau & 4 \\
\hline \multirow[t]{3}{*}{ Apakah aplikasi dapat dengan mudah dipelajari? } & Setuju & 24 \\
\hline & $\begin{array}{l}\text { Tidak } \\
\text { Setuju }\end{array}$ & 0 \\
\hline & Tidak Tau & 2 \\
\hline \multirow[t]{3}{*}{ Apakah aplikasi mudah dioperasikan? } & Setuju & 24 \\
\hline & $\begin{array}{l}\text { Tidak } \\
\text { Setuju }\end{array}$ & 0 \\
\hline & Tidak Tau & 2 \\
\hline \multirow[t]{3}{*}{ Apakah aplikasi bermanfaat bagi pengguna? } & Setuju & 19 \\
\hline & $\begin{array}{l}\text { Tidak } \\
\text { Setuju }\end{array}$ & 0 \\
\hline & Tidak Tau & 7 \\
\hline \multirow[t]{3}{*}{ Apakah tampilan menu mudah untuk dikenali? } & Setuju & 24 \\
\hline & $\begin{array}{l}\text { Tidak } \\
\text { Setuju }\end{array}$ & 0 \\
\hline & Tidak Tau & 2 \\
\hline \multirow{3}{*}{$\begin{array}{l}\text { Apakah aplikasi mempunyai kemampuan dan } \\
\text { fungsi sesuai yang diharapkan? }\end{array}$} & Setuju & 22 \\
\hline & $\begin{array}{l}\text { Tidak } \\
\text { Setuju }\end{array}$ & 0 \\
\hline & Tidak Tau & 4 \\
\hline
\end{tabular}

Hasil yang didapat melalui kusioner adalah sebagai berikut :

$\operatorname{Fr}=\mathrm{fi} \div \sum \mathrm{f} \times 100 \%$

1. 92,3\% responden mengatakan bahwa informasi yang disediakan aplikasi mudah dimengerti. 
2. $96,2 \%$ responden mengatakan bahwa fitur aplikasi mudah diguanakan.

3. $26,9 \%$ responden masih belum mengetahui manfaat yang dihasilkan untuk penguuna

\section{KESIMPULAN}

\section{A. Kesimpulan}

Kesimpulan yang dapat diambil dari aplikasi "Aplikasi Media Pembelajaran dan Pengenalan Alat Musik Gamelan” ini adalah sebagai berikut :

1. Berdasarkan data yang telah dipeoleh melalui kusioner, lebih dari $90 \%$ responden mengatakan bahwa aplikasi ini dapat membantu pengguna dalam memahami dan mempelajari berbagai jenis alat musik gamelan.

2. Aplikasi ini bisa mempermudah masyarakat atau user dalam memahami tentang pengertian dan fungsi dari jenis - jenis gamelan.

3. Data dari kusioner juga menunjukkan lebih dari $26 \%$ responden masih belum mengetahui manfaat untuk pengguna.

\section{B. Saran}

1. Pada aplikasi perlu ditamabahkan lebih banyak lagi jenis gamelan yang dibahas.

2. Perlu di tambahkannya tata cara memainkan dari masing-masing jenis gamelan.

3. Perlu di kembangkan tampilannya agar lebih menarik dan mudah dijalankan.

\section{DAFTAR PUSTAKA}

[1] Amperianto, T. (2014). Tips Ampuh Android. Elex Media Komputindo.

[2] F. Purnomo and J. Wiyoso, "Profil Kerajinan Gamelan Karya Indah di Dusun Tawang Desa Sempukerep Kecamatan Sidoharjo Kabupaten Wonogiri,” J. Seni Musik, vol. 6, no. 1, 2017.

[3] Ferdiansyah, F. (2010). Mengenal secara mudah dan lengkap kesenian karawitan (gamelan Jawa): disertai gambar-gambar peralatan karawitan, tembang Jawa, dan 302 istilah-istilah dalam karawitan Jawa. Garailmu.

[4] Haryono, Timbul. (2001). Sejarah dan Makna Gamelan. Yogyakarta: UGM press

[5] Latuheru, J. D. (1988). Media pembelajaran dalam proses belajar mengajar masa kini. Jakarta: Depdikbud.

[6] Satzinger, J. W., Jackson, R. B., \& Burd, S. D. (2015). Systems analysis and design in a changing world. Cengage learning.

[7] M. Subekti, L. Lukman, D. Indrawan, and G. Putra, "Perancangan Case Tools untuk Diagram Use Case, Activity, dan Class untuk Permodelan Uml Berbasis Web Menggunakan HTML5 dan PHP," ComTech Comput. Math. Eng. Appl., vol. 5, no. 2, p. 625, 2014, doi: 10.21512/comtech.v5i2.2199.

[8] S. Santoso and R. Nurmalina, "Perencanaan dan Pengembangan Aplikasi Absensi Mahasiswa Menggunakan Smart Card Guna Pengembangan Kampus Cerdas (Studi Kasus Politeknik Negeri Tanah Laut)," J. Integr., vol. 9, no. 1, pp. 84-91, 2017.

[9] I. Budiman, S. Saori, R. Nurul ANwar, Fitriani, and Dkk, "Analisis Pengendalian Mutu Di Bidang Industri Makanan," J. Inov. Penelit., vol. 1, no. 10, pp. 1-42, 2021. [9] I. Budiman, S. Saori, R. Nurul ANwar, Fitriani, and Dkk, “Analisis Pengendalian Mutu Di Bidang Industri Makanan,” J. Inov. Penelit., vol. 1, no. 10 , pp. 1-42, 2021.

[10] T. Tafonao, "Peranan Media Pembelajaran Dalam Meningkatkan Minat Belajar Mahasiswa," J. Komun. Pendidik., vol. 2, no. 2, p. 103, 2018, doi: 10.32585/jkp.v2i2.113. 